\title{
LINFANGIOMA CÍSTICO DO PÂNCREAS
}

\author{
CYSTIC LYMPHANGIOMA OF THE PANCREAS
}

\section{Glauco da Costa Alvarez, TCBC-RS ${ }^{1}$ \\ Marner Lopes da Silveira ${ }^{2}$ Eduardo Militz da Costa ${ }^{3}$}

\section{INTRODUÇÃO}

Linfangiomas são tumores benignos de tecido linfático, de origem provavelmente congênita, que são mais comuns nas regiões cervical e axilar, freqüentemente aparecendo em crianças. São incomuns em localização abdominal e extremamente raros no pâncreas ${ }^{1}$. Na literatura médica, o primeiro caso de linfangioma cístico de pâncreas foi relatado em 1962, por Gun, I ${ }^{2}$. Este relato objetiva mostrar este raro tumor, sua apresentação, métodos diagnósticos e tratamento.

\section{RELATO DO CASO}

Paciente do sexo masculino, branco, 47 anos, com história pregressa de acidente vascular cerebral há dez anos, procurou o Hospital Universitário com queixas de disúria e polaciúria há duas semanas. Ao exame físico não apresentava alterações, sendo feitos exame qualitativo de urina e urocultura, exames laboratoriais de rotina, que foram todos normais. Realizou ultra-sonografia (US) abdominal, que demonstrou formação cística de contornos irregulares e paredes finas, com septos, em localização epigástrica, posterior ao estômago e junto ao corpo do pâncreas. Realizou então exames de lipase e amilase, que também estavam normais. A tomografia computadorizada (TC) abdominal mostrou lesão expansiva, hipodensa, de contornos definidos, localizada na topografia da cabeça do pâncreas. Continha densidade líquida e sua superfície sofria reforço de luz após administração de contraste. Não havia evidência de dilatação dos ductos biliares. A hipótese diagnóstica era pseudocisto pancreático (Figura 1). À laparotomia exploradora, foi observada massa cística junto ao pâncreas aderida ao seu parênquima, mas sem comunicação e também sem aderências em vísceras adjacentes. A massa foi isolada totalmente sendo possível sua completa excisão. Macroscopicamente mostrou-se ser uma massa cística lisa e brilhante, medindo $7 \mathrm{~cm} x 4 \mathrm{~cm} \times 1,5 \mathrm{~cm}$ (Figura 2). À abertura, vários septos foram visualizados formando múltiplos cistos. À microscopia observaram-se cistos de vários tamanhos, com paredes finas e cobertos por um endotélio liso repleto de linfa, sendo diagnosticado linfangioma cístico de pâncreas. O paciente evoluiu sem complicações, com o desaparecimento dos sintomas no acompanhamento.

\section{DISCUSSÃO}

Existem três grupos histológicos de linfangiomas: capilar, cavernoso e cístico ${ }^{4}$. O linfangioma cístico pode se localizar em várias partes do corpo: região cervical $(75 \%)$, axilar (20\%), mediastino, pulmões, parede torácica, membros superiores, dorso, parótidas, baço, fígado, ossos, pele, retroperitônio e omento $(5 \%)^{1}$. Em crianças geralmente localizam-se no mesentério ou trato gastroin-

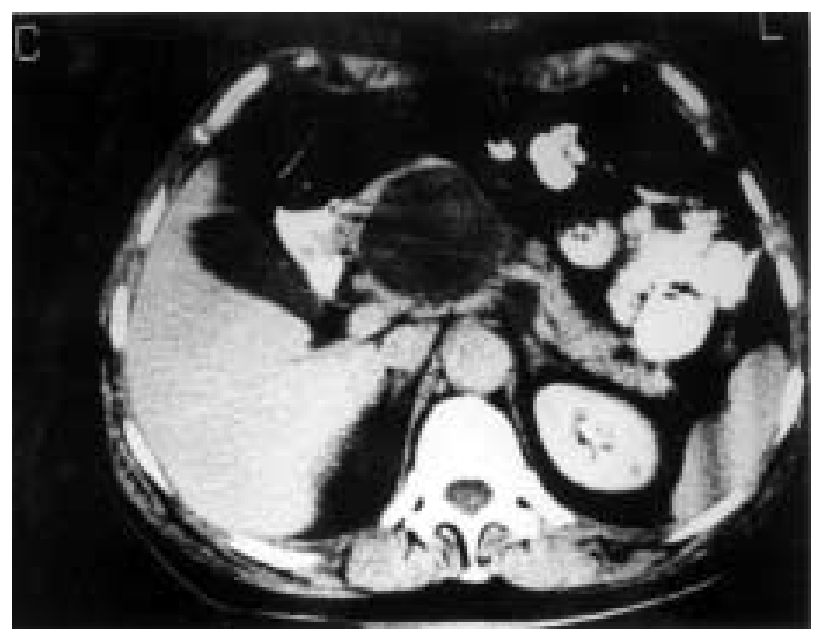

Figura 1 - Tomografia computadorizada abdominal, demonstrando a relação da massa cística com a cabeça, corpo e cauda do pâncreas.

1. Professor Assistente do Departamento de Cirurgia da UFSM-RS

2. Residente de Cirurgia Geral do Hospital Universitário de Santa Maria da UFSM-RS.

3. Médico formado pela UFSM.

Recebido em 7/10/1999

Aceito para publicação em 3/7/2000

Trabalho realizado no Departamento de Cirurgia da Universidade Federal de Santa Maria - UFSM-RS. 


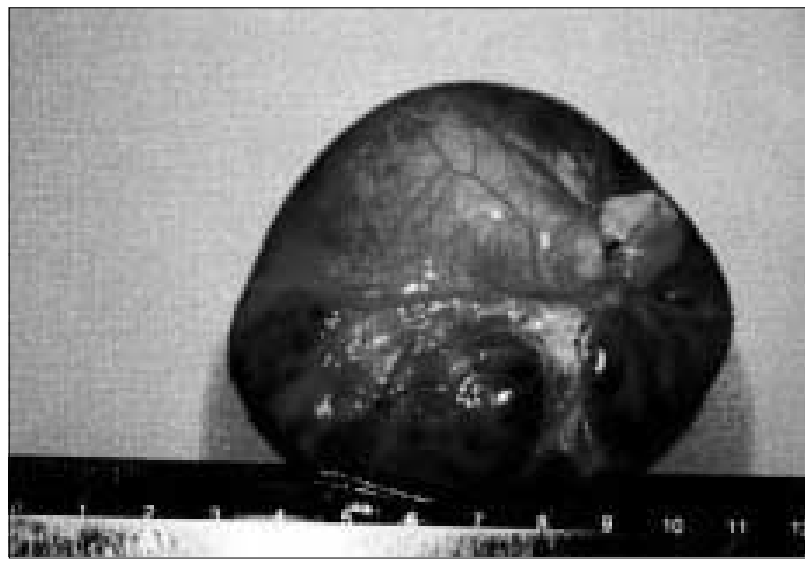

Figura 2 - Linfangioma cístico de pâncreas, produto de completa excisão.

testinal, podendo também ocorrer em adultos no retroperitônio ou em órgãos retroperitoniais ${ }^{1}$, como no pâncreas, relatado neste caso. O linfangioma cístico é caracterizado histologicamente por um acúmulo de cistos de tamanhos variados, com finas camadas que contêm tecido linfóide e músculo liso, cobertas por um endotélio liso ${ }^{5}$.

Os linfangiomas císticos não apresentam sintomatologia característica. Na maioria das vezes são assintomáticos, ou são descobertos acidentalmente ${ }^{4}$, como descrito neste relato. Sintomas ocorrem geralmente devido à compressão de órgãos adjacentes ou com o crescimento do tumor, causando distensão e dor abdominais ${ }^{5}$. Podem ocorrer sintomas agudos devido à ruptura, torção, hemorragia e infecção do cisto, além de obstrução intestinal, levando a um quadro de abdome agudo ${ }^{4,5}$.

O método diagnóstico inicial para investigação de cistos pancreáticos é a ultra-sonografia abdominal, seguida da tomografia computadorizada, necessária para identificar a relação com órgãos vizinhos e/ou o envolvimento de estruturas adjacentes ${ }^{1,4,5}$. A arteriografia do tronco celíaco e artéria mesentérica superior pode mostrar compressão vascular com hipervascularização desorganizada, lago venoso e retorno venoso precoce. O estudo radiológico do trânsito intestinal com bário pode demonstrar compressão extrínseca do duodeno ou estômago, dependendo do tamanho ou localização da massa tumoral ${ }^{5}$. O diagnóstico final de linfangioma é dado pelo exame histopatológico ${ }^{4}$.

O tratamento de escolha para o linfangioma cístico é a total excisão do tumor ${ }^{1,4,5}$. Existindo invasão de outros órgãos, a excisão deve incluir a área afetada do órgão vizinho ${ }^{1}$. Aspiração, cistoenterostomia e marsupialização do cisto com a cavidade peritoneal são geralmente seguidos de recorrência precoce ${ }^{1}$. Em um estudo realizado por Hebra et al. ${ }^{3}$, a ressecção parcial está associada com alta recorrência, 50\% em dois anos de acompanhamento, enquanto que a excisão total apresenta recorrência abaixo de $7 \%$.

\begin{abstract}
Lymphangiomas are benign neoplasias of lymphatic tissue, extremely rare in the pancreas. Three lymphangioma types exist: capillary, cavernous and cystic. The authors report a case of cystic lymphangioma of the pancreas, with incidental diagnosis to the abdominal ultrasonography on investigation of urinary symptoms in male patient. To the laparotomy upper cystic mass was identified in the pancreas, that was totally resected. The histological examination demonstrated a cystic lymphangioma of the pancreas. The cystic lymphangioma of the pancreas was discovered accidentally, being assintomatic in most of the cases. Treatment of choice is complete resection, otherwise recidive is higher than 50\%.
\end{abstract}

Key Words: Cystic; Lymphangioma; Pancreas.

\section{REFERENNCIAS}

1. Perrot M, Rostan O, Morel P, et al - Abdominal lynphangioma in adults and children. Br J Surg, 1998; 2:385-95.

2. Gun I, Schumer W, Veiga $S$ - Cystic lymphangioma of the pancreas: marry report. Ill $M J, 1962 ; 1: 651-53$.

3. Hebra A, Brown M, McGeehin K, Ross A - Mesenteric, omental, and retroperitoneal cysts in children: the clinical study of 22 marries. South Med J, 1993; 86: 173-6.

4. Khandelwal M, Lichtenstein GR, Morris JB, et al - Abdominal lymphangioma masquerading the pancreatic cystic neoplasm. J Clin Gastroenterol, 1995; 20(2):142-4.
5. Letoquart JP, Marcorelles P, Lancien G et al - Unnouveau lymphangioma cas kystique du pancréas. J Chir (Paris), $1989 ;$ 126(12): 650-8.

Endereço para correspondência:

Dr. Glauco da Costa Alvarez

Rua Pinheiro Machado 2350/conj. 408

97050-600 - Santa Maria-RS

E-mail: anassma@zaz.com.br 